\title{
An engineered alternative brick masonry unit for the poor inhabitants at Hawassa village, Ethiopia
}

\author{
J Jebasingh Daniel*, Desta Basoro and Mehretu Gebrie \\ Department of Civil Engineering, Institute of Technology, Hawassa University, Hawassa, Ethiopia
}

Received: 20-May-2021; Revised: 24-June-2021; Accepted: 25-June-2021

(C)2021 J Jebasingh Daniel et al. This is an open access article distributed under the Creative Commons Attribution (CC BY) License, which permits unrestricted use, distribution, and reproduction in any medium, provided the original work is properly cited.

\begin{abstract}
The southern rural regions of Hawassa village, Ethiopia customarily practices Chika-pet and adobe masonry houses. They use soil, wood and teff straw adobe bricks in house construction, due to its extreme poverty and unsophisticated manner of living. These houses are unsustainable and flimsy due to its inclusion of easily degradable raw materials, non-engineered construction practice, poor earthquake resistance and rapid climatic uncertainties. Moreover, the soil utilized for the adobe brick making is consumed from far away distant regions by ignoring their native Hawassa soil due to its unsuitable brick making characteristics. This impacts the economical expenditure of the poor income inhabitants. Therefore, this research is intended to facilitate the Hawassa village inhabitants by improving their native soil characteristics on adding lime and considers it for brick unit formation. In addition, an alternative reinforcement called pineapple leaf fibre is introduced for the adobe brick making which enriches compressive and tensile strength at a satisfactory rate according to the California Building Standard Code (CBC) requirement. The maximum compressive strength is recorded as 4.1 MPa which is 6 times greater than the conventional specimens and flexural strength is recorded at an improved rate of 0.78 Mpa. It ensures the standard requirement according to the $\mathrm{CBC}$ code. As a result, a sustained residual tensile load is recorded which indicates an efficient improvement in the ductility failure of brick. The bending test data is processed to estimate young's modulus in tension highlighting the bi-modularity of the earthen composite material. The experimental correlation between various mechanical properties is presented and modelling design equations are proposed in the engineered manner of design/assessment purposes. A comparative study and cost analysis of the existing and proposed approach is discussed to validate the superiority of the proposed concept.
\end{abstract}

\section{Keywords}

Rural development, House construction development, Brick masonry units, Adobe brick, Poor inhabitants, Economical construction materials.

\section{Introduction}

1.1Background of the study

The traditional house construction pattern in the southern rural regions of Ethiopia is preferably constructed by means of "Chika-pet", which is the mud and wood construction technique, due to the poverty and low annual income of the inhabitants. "Chika" is a composite mixture of clay, teff straw and water, that is used as a gap filling material between the wooden frames and finally as a plaster. Due to the climatic uncertainties, this mud wall construction pattern experiences severe shortcomings such as wide crack formation in the walls, shrinkage, strength weakening, and prone to be eroded by rain which deteriorates the durability.

\footnotetext{
*Author for correspondence
}

Later on, to cope with these drawbacks the animal dung is used as a protective coating on the Chika-pet house walls. It further requires frequent maintenance and cost wise unaffordable by the inhabitants. Moreover, these houses require plenty of woods for the construction of walls and roofs which increases the cost and deforestation rate, hence these mud walls using soil is considered to be defective.

Recently, the advancement of house construction in the southern regions of Ethiopia is upgraded by using bricks as the construction material. In current practice, the brick masonry units are made of a composition of soil and teff straw fibre, wherein the soil is preferably collected from the far distance regions like Ziway, Alemtena and Meki. The negligence of their native southern region soil is due to its poor brick construction characteristics and hence this complicates 
the economical expenditure of the low-income inhabitants with increased rate of transportation cost.

The bricks in current practice are formed in larger size and this leads to increased heaviness with decreased strength [1]. Moreover, the durability and strength of the building is affected over years later due to the decomposition of teff straw present in the bricks which causes higher porosity [2]. This demerit the building structure by becoming more brittle and leads to poor performance during the seismic condition [3].

This research focus and address the major setbacks in the construction engineering such as uneconomic expenditure affecting poorly income people, increased rate of deforestation, reliance on Chika-pet, demerits of teff straw, rejection of native soil, weedy and nonengineered construction practices, unnecessary transportation expenditure, instability of the building during seismic situation, durability and eco friendliness of unfired mud brick houses need broad exploration.

The main objective of this study is to provide an economical, eco-friendly and sustainable brick masonry unity for the poor inhabitants of Hawassa village. To achieve this major objective, the compressive strength, tensile strength, residual load and durability test were conducted on the proposed masonry samples and compared with the conventional practice of masonry units. In addition, to calculate the mechanical properties and design the brick manually, experimental correlations between various mechanical properties were explored and modeling, design equations were proposed in the engineered manner of design/as ses sment purposes. A comparative study and cost analys is of the existing and proposed approach is discussed to validate the superiority of the proposed concept.

\section{Literature review}

Numerous researchers have reported different fibre compositions in the making of adobe bricks and its characteristics like compressive strength, flexural strength, modulus of elasticity, water absorption test, thermal conductivity etc. are tested and analysed for ensuring the efficacy of the fibre. Babé et al. (2020) addressed the influence of red millet fibres on the compressive and flexural strength of adobe mixes. The experimental test result of mechanical characteristics confirms that the inclusion of $2 \%$ millet fibres to the soil of adobe brick enhances the compressive and flexural strength at a rate of $38 \%$. Also, incorporation of 2 to $4 \%$ addition of millet fibre to the soil of adobe brick shows more resistant composite while compared with the adobe brick made of pure matrix soil [1].

The mechanical properties with the addition of sea grass fibres to the soil of adobe brick was studied [2]. The experimental test result concludes that both the compressive and flexural strength of adobe brick is improved due to the addition of sea grass fibres. It is recorded that the maximum compressive and flexural strength of adobe brick is $2.672 \mathrm{MPa}$ and $0.457 \mathrm{MPa}$, respectively corresponding to the addition of $1.5 \%$ of seagrass whose length is equal to $3 \mathrm{~cm}$.

Bertelsen et al. (2021) [3] reveals that the usage of synthetic waste fibres in adobe brick results in the formation of finer cracks as compared to the wider cracks generated on employing unreinforced specimen. On increasing the synthetic fibre content along the adobe brick the flexural strength increases, accordingly. It perceived that the addition of $5 \%$ synthetic fibre produces $75 \%$ superior flexural strength as compared to the conventional adobe brick. Similarly, the compressive strength increases $33 \%$ with respect to unreinforced specimen due to the addition of fibre content.

The influence of adding recycled pet fibres along with adobe bricks was investigated by literature [4] in terms of drying shrinkage and compressive strength effects. The experimental results ensure an encouraging effect on both properties while adding 0.25 to $0.5 \%$ fibres and a reduction of shrinkage is recorded up to $48 \%$. Moreover, the highest compressive strength is reported corresponding to $0.5 \%$ of fibre with higher clay content.

Ige and Danso (2021) [5] focused on the solution to develop mechanical properties of adobe bricks with plantain pseudo-stem fibre. The experimental laboratory test was conducted on different ratio of fibres at $0,0.25,0.5,0.75$ and $1 \%$ in addition to adobe bricks. The average compressive strength is obtained as $1.76 \mathrm{MPa}$ corresponding to $0.75 \%$ inclusion of fibre with $33 \%$ enhanced compressive strength over the pure matrix form of adobe brick. The $0.5 \%$ inclusion of plantain pseudo-stem fibre reinforced adobe brick attained maximum splitting tensile strength of $0.3 \mathrm{Mpa}$ which is $53 \%$ enhanced strength over unreinforced brick.

Kafodyaab et al. (2019) [6] conducted an investigation by including sisal fibres as a reinforcing element for adobe masonry. A $25 \mathrm{~mm}$ length fibre is added at $0.75 \%$ and its experimental results reveal a $31 \%$ 
increase of tensile strength and $25 \%$ increase of prism compressive strength as compared to the unreinforced mortar. Moreover, the sisal fibre wallets exhibit a two times enhancement in compressive strength and the reinforced wall panels records three times raise in shear strength.

The fonio straw is investigated on the mechanical properties of adobes and its laboratory experimentation was performed by Ouedraogo et al. (2019) [7]. The usage of small amount of fonio straw enhances the compressive strength, flexural strength and reduces the brittleness of the adobes. The maximum strength is attained corresponding to 0.2 to $0.4 \%$ weight of fonio straw content. Besides, the thermal conductivity of adobes decreases during the addition of fonio straw due to the insulating nature of cellulose in the straw and the straw inclusion has a property to resist water erosion of adobe brick.

The mechanical properties of adobe brick composed of paper and pulp waste fibre were investigated [8]. The light weight adobes with lesser thermal conductivity and enhanced compressive strength are created by employing paper and pulp waste fibre. The compressive strength is superior up to $190 \%$, while thermal conductivity diminishes $30 \%$ to $12.5 \%$ of fibre replacement.

Sudhir et al. (2020) [9] conducted a research on focusing the utilization of industrial waste fibre for the production of adobe bricks. Here, the compressive strength increases $40.10 \%$ maximum up to the addition of $60 \%$ industrial waste and beyond the compressive strength reduces. The researchers reported that the usage of red mud as a brick manufacturing material is economically feasible and cured bricks are eco-friendly as compared to conventional fired bricks.

Malkanthia et al. (2020) [10] states that the unfired adobe brick requires less energy than the fired bricks and the emission of $\mathrm{CO} 2$ to the environment is $80 \%$ less as compared to the burnt bricks. This is evident from the Figure 1 which graphically represents the increased rate of initial embodied energy and pollution emission per one cubic meter for various types of fire brick walls. CSEB indicates the Compressed Stabilized Earth Blocks. The cement is considered as the most admired stabilizer than the lime for earth block manufacturing. On comparing the production process of lime and cement, the emission rates of energy and $\mathrm{CO}_{2}$ are recorded at higher values for the cement as compared to lime for a cubic meter of material quantity as mentioned in the Figure 2.

The existing literatures reveal that the authors significantly focus on the mechanical property investigation of the adobe bricks with the composition of variant type of fibres. However, the literatures fail to discover the relationship between the mechanical properties such as compressive strength, flexural strength, modulus of elasticity, etc. which facilitates the designer to design the bricks without conducting any laboratory testing. Furthermore, the reinforcement fibres like red millet, sea grass, industrial waste, synthetic waste, recycled pet, paper and pulp waste, plantain pseudo-stem, sisal, and fonio straw are employed for the brick making process, which lacks their easy and continuous availability in Ethiopia.

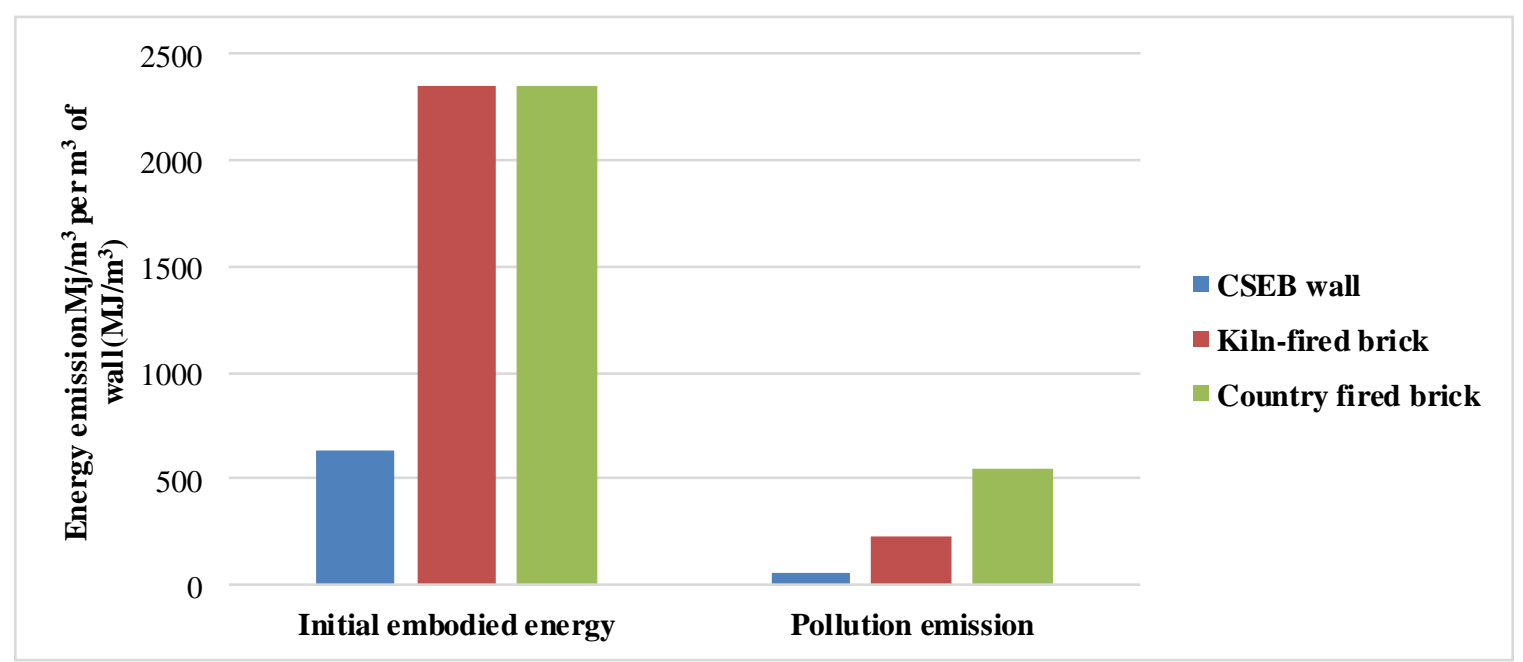

Figure 1 Initial embodied energy and pollution emission of wall [10] 
J Jebasingh Daniel et al.

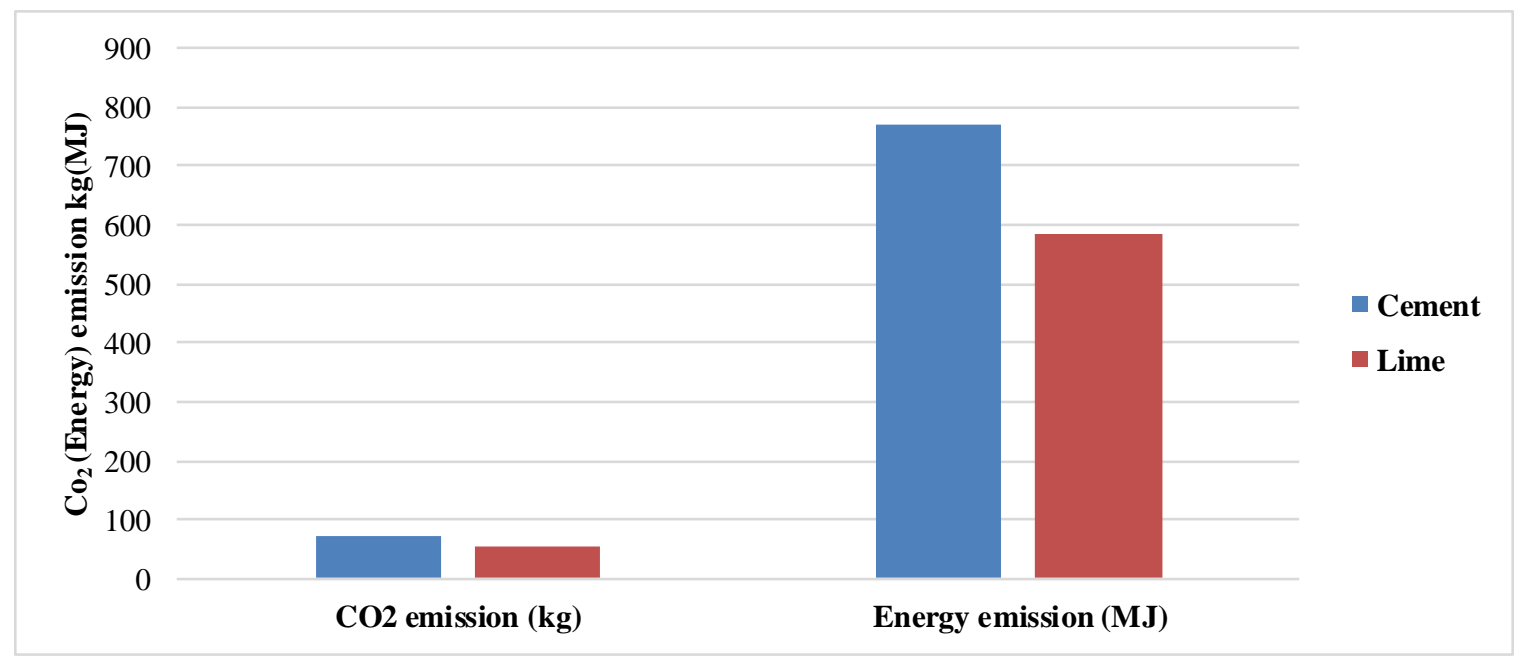

Figure 2 Emission rates of $\mathrm{CO}_{2}$ and energy during lime and cement blocks manufacturing [10]

This paper is highly intended to develop and propose the brick design equations based on the mechanical property relationships, which in turn simplifies the design engineer in the brick making process. This study not alone limited to the calculation of compressive strength, flexural strength, modulus of elasticity, but also explored the experimental correlation between various mechanical properties and modelling design equations are proposed in the engineered manner of design/assessment purposes. Correspondingly, these design equations help the designer to calculate the mechanical properties like compressive strength, flexural strength, modulus of elasticity etc. without conducting any laboratory experimentation. In addition, the economically feasible and easily available pineapple leaf fibre is used as a reinforced material for adobe brick making. Moreover, an eco-friendly binding agent called lime is used to improve the Hawassa soil property which requires lesser energy emission and is cheaper while compared with cement. A comparative study and cost analysis of the existing and proposed approach is discussed to validate the superiority of the proposed concept.

\section{Materials}

3.1Variables, availability and price of stabilizer and reinforcing material in Hawassa

The major variables considered in the experimental study include stabilizer called lime and reinforcing material called pineapple leaf fiber in total weight. Massive production resources of lime are found in Ethiopia and the lime is economically feasible at a rate around five Ethiopian Birr per one kilogram. This is afforded by the inhabitants as the requirement of lime for one masonry unit is in very small quantity. Around
50 years ago, pineapple cultivation is established in the Ethiopian Sidama region (Hawassa) and it is the only region generates large quantities of pineapple fruits for local markets from the farm land due to its warm climatic condition as well as soil suitability [11]. From the mass production of pineapple leaf, lesser amount of leaf fibers is used as feedstock and employed for energy production, whereas the majority are wasted as residues from the agro based industries. Fortunately, these leaf fibers possess various beneficial features suitable for brick making [12], yet it is not used so far in un-burnt brick making process in Hawassa due to unawareness about its advantages. Therefore, this research proposes the pineapple leaf fiber as a reinforcing material for the brick manufacturing.

\subsection{Hawassa soil sample}

The southern regions of Ethiopia generally prefer the soil from Ziway, Alemtena and Meki regions for the construction purpose of brick masonry unit. The underlying fact of this soil preference is that, it complicates the economical expenditure of the lowincome inhabitants of Hawassa village with increased rate of transportation charges. Due to the poor brick construction characteristics of Hawassa soil, it is generally not preferred for brick formation. Hence, this research facilitates the Hawassa inhabitants by improving their native soil quality with altered characteristics and considers it for brick unit formation. This alteration is performed by adding binder material called lime. The test sample soil is collected from the main campus of Hawassa University for the production of un-burnt brick as shown in the Figure 3. The characteristics of the collected soil sample are studied by performing Geotechnical analysis. Moreover, the physical 
properties like Particle size distribution of the experimenting soil are tabulated in Table 1, optimum water content $15.40 \%$, Liquid limit $30.6 \%$, plastic limit $23.30 \%$ and plasticity index $7.30 \%$ are investigated and identified under laboratory testing as represented in the Figure 3. The test results ensure an adequate amount of plasticity for a uniform mix when added with other ingredients to the mixture.

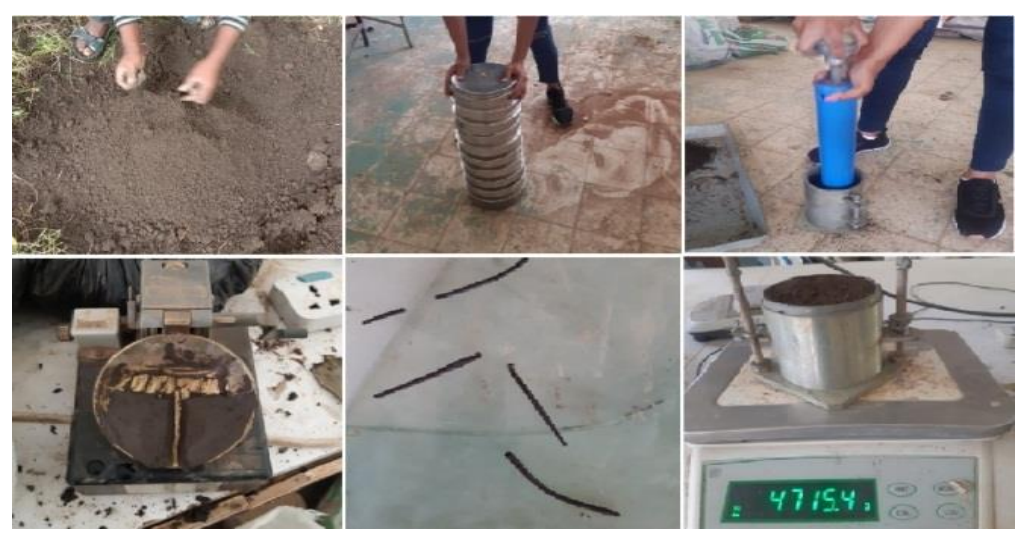

Figure 3 Laboratory soil testing

Table 1 Particle size distribution of the experiment soil

\begin{tabular}{ll}
\hline Sieve opening $(\mathbf{m m})$ & Percentage of passing \\
\hline 9.5 & 99.42 \\
\hline 4.75 & 92.33 \\
\hline 2.36 & 76.29 \\
\hline 2 & 76.29 \\
\hline 1.18 & 55.60 \\
\hline 0.6 & 31.29 \\
\hline 0.425 & 31.29 \\
\hline 0.3 & 18.84 \\
\hline 0.15 & 10.89 \\
\hline 0.075 & 4.57 \\
\hline Pan & 0.00 \\
\hline
\end{tabular}

\subsection{Reinforced composite-pineapple leaf fibre}

Due to the excellent physical and mechanical characteristics of pineapple leaf fibre [11], it is used as a reinforcing composite matrix for the masonry units as pictured in Figure 4. It is considered as an efficient alternative for teff straw fibre [12]. The extraction process of fibres from the pineapple leaf is performed by the mechanical and retting method. The result of polymer composite pineapple leaf fibre confirms an excellent stiffness and strength as compared to other cellulose based compound materials [13]. The various dynamic features of pineapple leaf fibre include robust mechanical strength, good sound absorbent, thermal insulator, soft and glossy as silk, medium length fibre, high tensile strength, stiffness, softer exterior surface than other natural fibres and good colour maintenance [14]. The mechanical property of pineapple leaf fibres such as young's modulus varies from 34.5 to 82.51 $\mathrm{GN} \cdot \mathrm{m}-2$, tensile strength varies from 413 to 1627 $\mathrm{MN} \cdot \mathrm{m}-2$ and elongation at breakpoint varies from 0.8 to $1.6 \%$. The physical and mechanical strength of pineapple leaf fibre is mentioned in the Table 2. The percentage weight of pineapple leaf fibre considered in this study varies from $0.1 \%, 0.2 \%, 0.3 \%, 0.4 \%$, $0.5 \%, 0.6 \%, 0.7 \%, 0.8 \%, 0.9 \%$ and $1 \%$ in total weight of masonry units. 
J Jebasingh Daniel et al.

Table 2 Properties of pineapple fibre

\begin{tabular}{lllll}
\hline Density $\left(\mathbf{g} / \mathbf{c m}^{\mathbf{3}}\right)$ & $\begin{array}{l}\text { Average } \\
(\boldsymbol{\mu m})\end{array}$ & diameter & $\begin{array}{l}\text { Tensile } \\
\text { strength } \\
(\mathbf{M P a})\end{array}$ & $\begin{array}{l}\text { Young's } \\
(\mathbf{G P a})\end{array}$ \\
\hline 1.35 & 227 & 52 & 2.42 \\
\hline 1.4 & 61.87 & 238 & 53 & 2.52 \\
\hline 1.3 & 63.2 & 221 & 49 & 2.34 \\
\hline 1.5 & 58.6 & 254 & 56 & 2.69 \\
\hline 1.45 & 67.5 & 243 & 53 & 2.58 \\
\hline
\end{tabular}

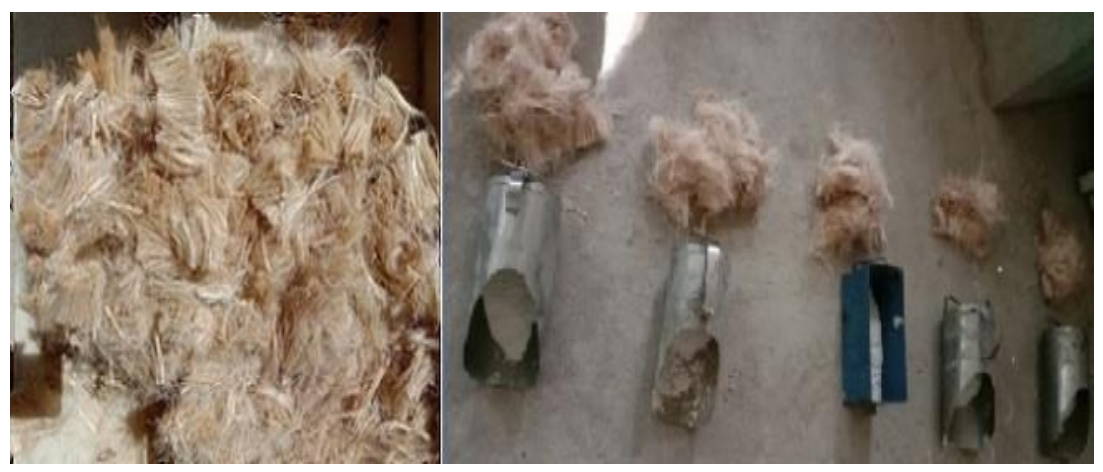

Figure 4 Pineapple leaf fibres

\subsection{Stabilizer-lime}

Lime, an antique and economic material predominantly used as a soil stabilizer, which has its abundant natural resource in Ethiopia. On blending the lime content in the clay soil, the natural property of the soil gets improved due to the reaction of the calcium ion content in the lime with the clay soil. At this phenomenon, there is an exchange between metallic ion and cat ion which alters the electric charge density of the particles and tightly groups them in the form of flocks. The various percentage composition of lime weight considered are $1.5 \%, 3 \%, 4.5 \%, 6 \%, 7.5 \%, 9 \%$, $10.5 \%, 12 \%, 13.5 \%$ and $15 \%$ in total weight of masonry units.

\section{Methodology}

The methodological schematic of this experimental investigation was presented in Figure 5, which includes sample collection, manufacturing of bricks, laboratory testing, analysis of test results and development of design equations. In order to develop an engineered customized design equation for adobe brick production. It is mandatory to perform laboratory experimentation for calculating the mechanical properties such as compressive test, flexural test, modulus of elasticity, etc. These test results facilitate in estimating the relationship or correlation between each mechanical property by performing a regression analysis. The design equations are structured based on the correlation property of each parameter, which helps the design engineers in future in estimating the different mechanical properties without conducting any experimentation.

An efficient brick modeling with high durability is tested by considering various proportional ratios of the constructing ingredients as presented in the Table 3 detailing three groups of masonry unit making process. The first group of masonry unit production includes the combination of soil and lime illustrated in Figure 6(a), whereas the second group includes the combination of soil and fibers as shown in Figure $6(b)$. The production process of these brick specimens includes grinding, mixing, manual molding and sun drying. Further the mechanical properties of group 1 and 2 adobe bricks are calculated using laboratory testing. Based on the test results of first and second group brick productions, the percentage ratio of mixing composition of third group specimen made of soil, lime and pineapple leaf fiber is identified and presented in Figure $6(c)$. Similarly, the group 3 specimen is treated under production process and laboratory testing, which finally concludes that group 2 and 3 are efficient and is considered as proposed 1 and 2 respectively. In current practice, the standard existing size of the brick measures $400 \times 200 \times 200 \mathrm{~mm}$, whereas this investigation considers a brick size of $240 \times 112 \times 70 \mathrm{~mm}$ measurement which considerably reduces the heaviness as compared to the existing bricks and casting and drying process of brick 
specimen is pictured in the Figure 7. The laboratory experimentation is performed to examine the compressive strength, tensile strength and durability testing on rain. In addition, the ductility nature of the brick specimen towards the seismic condition also studied using tensile load versus displacement curve. The experimental results obtained using the reinforcement pineapple leaf fiber is compared with the existing teff straw fiber composition.

Table 3 Group and specimen composition of adobe brick

\begin{tabular}{lllllllll}
\hline Group-1 & \multicolumn{3}{c}{ Group-2 } & \multicolumn{3}{c}{ Group-3 } \\
\hline $\begin{array}{l}\text { Brick } \\
\text { specimen }\end{array}$ & $\begin{array}{l}\text { Lime } \\
\mathbf{( \% )}\end{array}$ & $\begin{array}{l}\text { Fibre } \\
\mathbf{( \% )}\end{array}$ & $\begin{array}{l}\text { Brick } \\
\text { specimen }\end{array}$ & $\begin{array}{l}\text { Lime } \\
\mathbf{( \% )}\end{array}$ & $\begin{array}{l}\text { Fibre } \\
(\boldsymbol{\%})\end{array}$ & $\begin{array}{l}\text { Brick } \\
\text { specimen }\end{array}$ & $\begin{array}{l}\text { Lime } \\
(\boldsymbol{\%})\end{array}$ & $\begin{array}{l}\text { Fibre } \\
(\boldsymbol{\%})\end{array}$ \\
\hline L1 & 1.5 & & F1 & - & 0.1 & L5F1 & 0.9 & 0.1 \\
\hline L2 & 3 & - & F2 & - & 0.2 & L5F2 & 0.9 & 0.2 \\
\hline L3 & 4.5 & & F3 & - & 0.3 & L5F3 & 0.9 & 0.3 \\
\hline L4 & 6 & - & F4 & - & 0.4 & L5F4 & 0.9 & 0.4 \\
\hline L5 & 7.5 & & F5 & - & 0.5 & L5F5 & 0.9 & 0.5 \\
\hline L6 & 9 & - & F6 & - & 0.6 & L5F6 & 0.9 & 0.6 \\
\hline L7 & 10.5 & & F7 & - & 0.7 & L5F7 & 0.9 & 0.7 \\
\hline L8 & 12 & - & F8 & - & 0.8 & L5F8 & 0.9 & 0.8 \\
\hline L9 & 13.5 & & F9 & - & 0.9 & L5F9 & 0.9 & 0.9 \\
\hline L10 & 15 & - & F10 & - & 1 & L5F10 & 0.9 & 1 \\
\hline
\end{tabular}

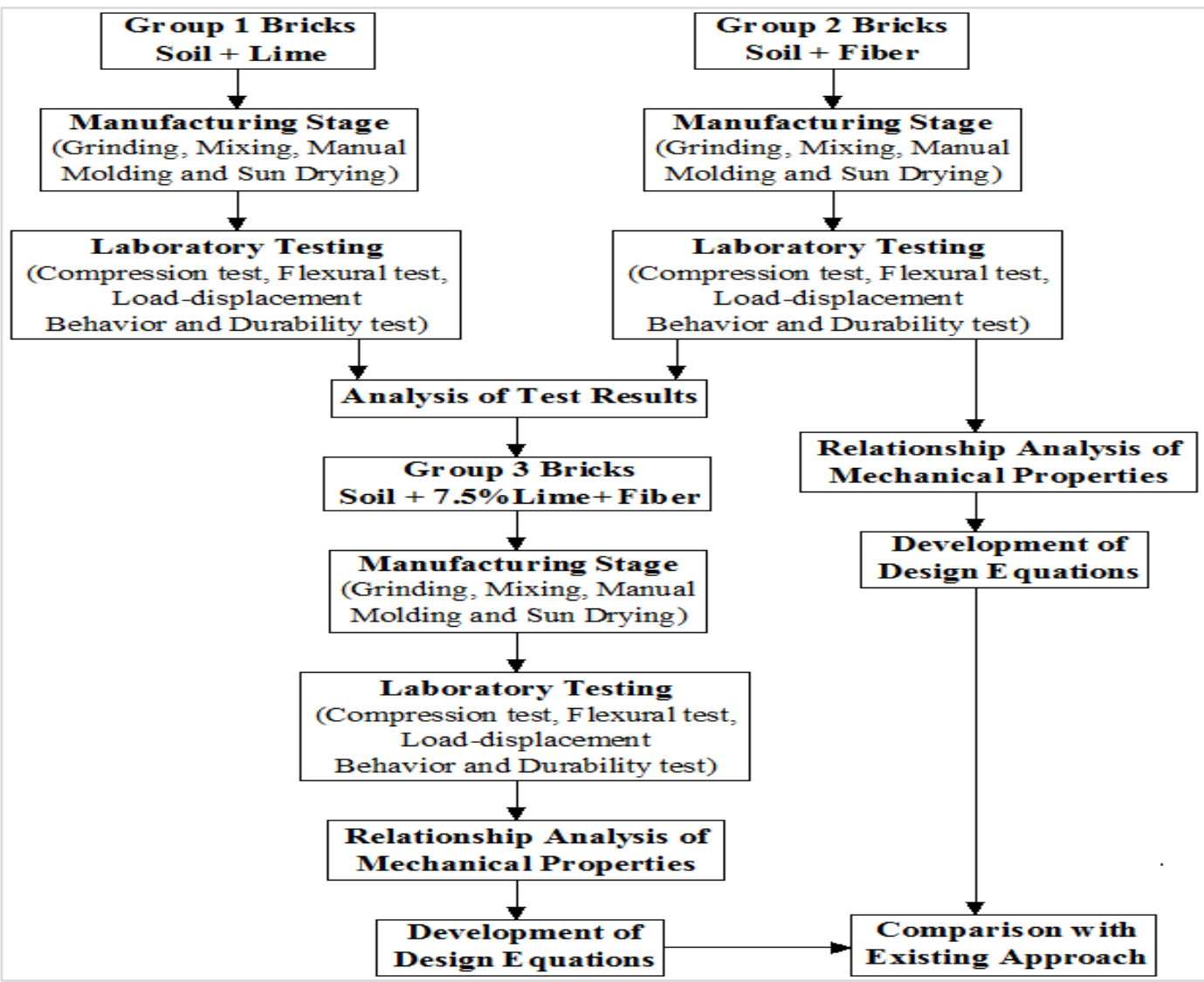

Figure 5 Methodological schematic flowchart 


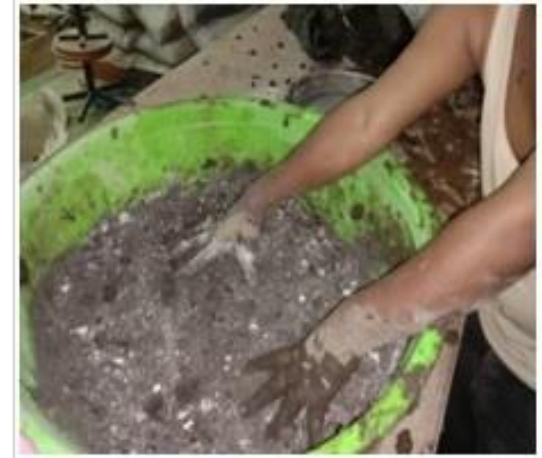

a) Group 1

(Soil + Lime)

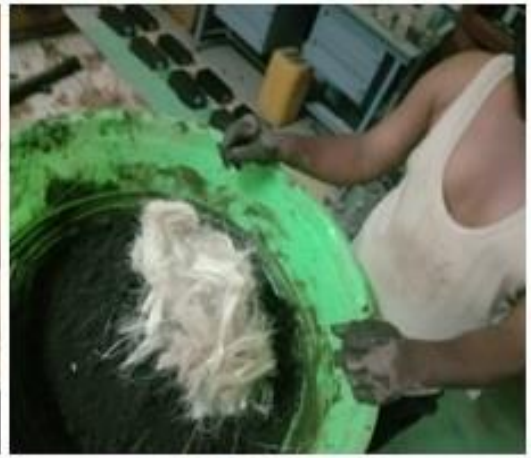

b) Group 2 (Soil + PineappleFiber)

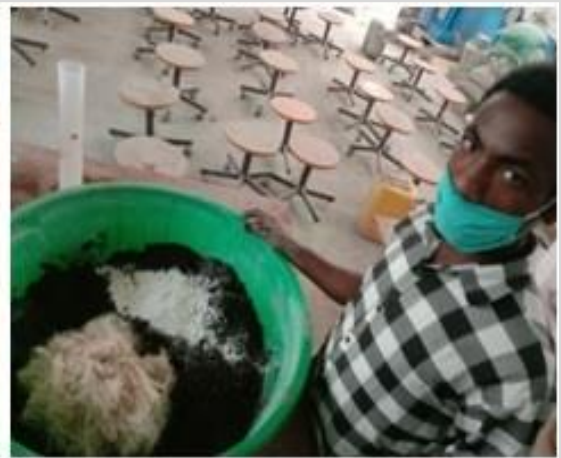

c) Group 3

(Soil + Lime + Pineapple Fiber)

Figure 6 Various group of composition of adobe brick specimen
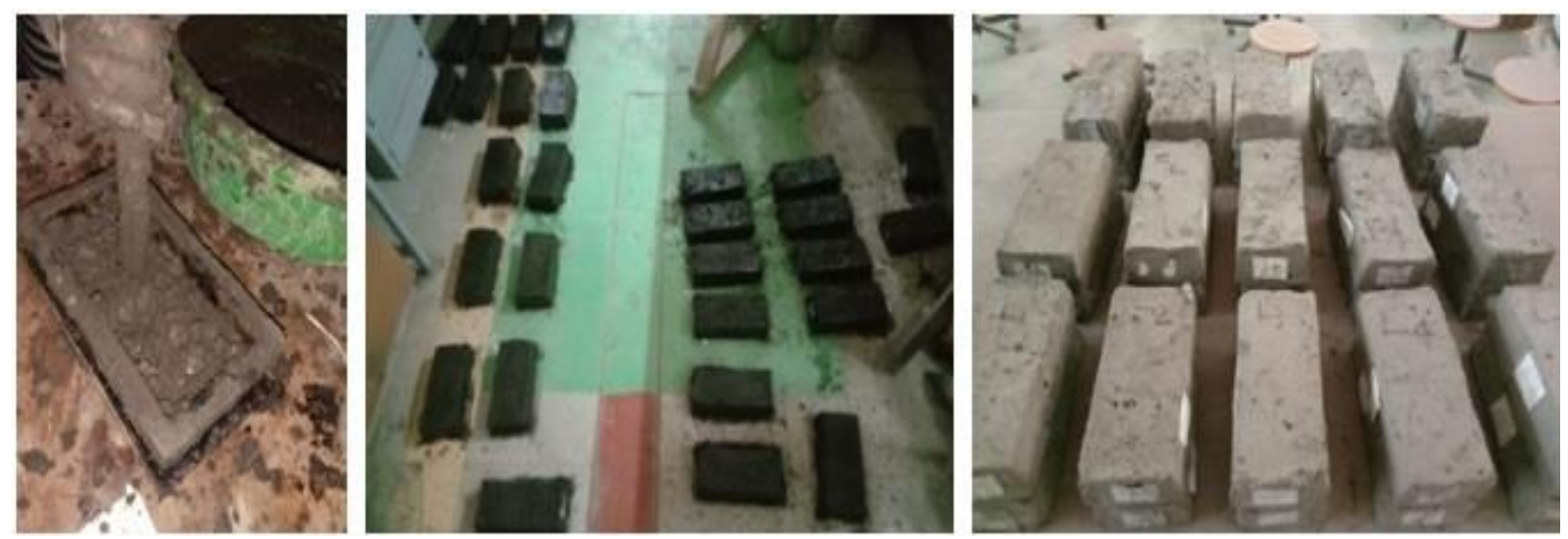

Figure 7 Making process of brick specimen

\subsection{Uniaxial compression tests}

The mechanical behaviour of un-burnt bricks in uniaxial compression are distinguished using the displacement controlled uniaxial testing machine as per the European standard [15]. The brick specimen of size $240 \times 112 \times 70 \mathrm{~mm}$ is located between stiff rigid steel plates on the testing machine. The loading process includes two initial cycles of loading, which follows by a displacement- controlled monotonic loading at a displacement rate of $0.01 \mathrm{~mm} / \mathrm{s}$ and the load measurements are straightforwardly applied by the test machine in digital form. Correspondingly, the axial deformation of adobe brick specimens is observed and measured by using four linear variable differential transducers which are fixed on the corner of the rigid end plates of the machine. It is noted that Linear Variable Differential Transducers (LVDT) readings provide the same average displacements of the specimen. The uniaxial compression test is conducted in three stages of brick specimen as mentioned in the Table 3, from which the stress strain curves are drawn to reveal the significance of compressive stress variation. Moreover, the elastic modulus, peak compressive strength and axial strain at peak compressive stress are calculated.

4.2Modulus of rupture (Three-Point Bending test) The Modulus of Rupture (MOR) is the transverse rupture strength and is generally referred as the ability to resist bending stress. The mechanical behaviour of pineapple leaf fibre reinforced adobe brick in tension is examined by means of three-point flexural test. MOR testing is conducted on stage 1 and 2 specimens of size $240 \times 112 \times 70 \mathrm{~mm}$ according to European standard EN 1015-11. The universal compression testing machine is used to perform the bending strength test of all specimens and each specimen is positioned upon the steel prop-up to attain the clear span of $220 \mathrm{~mm}$, in which a point load is applied gradually in the mid span section of the specimen. As similar to compression test, the load-deflection curves are drawn by performing displacement-controlled monotonic loading at a displacement rate of $0.01 \mathrm{~mm} / \mathrm{s}$ and the digital indication of the applied load in test 
machine is noted. According to EN 1015-11 [16], the flexural strength of masonry units can be calculated using the Euler-Bernoulli beam theory of uniaxial bending as shown in Equation 1.

$f_{t}=\frac{3 P L}{2 w d^{3}}$

Where, $\mathrm{P}$ - the maximum load indicated by the machine, L - the span length between the supports, $\mathrm{w}$ and $\mathrm{d}$ - the width and depth of the trans verse section of the specimen at failure.

The code standard [16] permits to neglect the arching action of the specimen during testing due to the short span to depth ratio. Nevertheless, currently there is no regular guideline rules are available for the conversion of deflection to tensile strain which is measured at the bottomof the testing specimen. According to the s tudy [17], it is assumed that the pineapple leaf fibre reinforced earth brick specimen has two different elastic modulus values under uniaxial bending test, wherein one is on the compression and another one at the tension. This assumption is based on the most materials experience different strain values at compression and tension zone of the specimen under uniaxial bending test. The tensile modulus of brick specimen is calculated using Equation 2.

$E_{t}=\frac{P L^{3}}{4 \delta \mathrm{w}^{3}}$

Where $\delta$ is the maximum deflection at the mid span of the specimen. The ratio of tensile elastic modulus to the compressive elastic modulus is symbolize by $\mathrm{n}$ as shown in Equation 3.

$\mathrm{n}=\frac{\mathrm{E}_{\mathrm{t}}}{\mathrm{E}_{\mathrm{c}}}$

\section{Experimental results}

5.1Effect of fibre and lime content on the compressive strength

The compressive test is conducted for three groups of brick specimens as shown in Figure 8(a), (b) and (c). The first group of specimen consists of soil and lime, wherein the percentage composition of lime is considered as variable in a range of $1.5 \%$ to $15 \%$. The second group comprises of soil and fibre, in which the fibre varies from $0.1 \%$ to $1 \%$. The third group is a combination of soil, lime and fibre, here the percentage variation of lime and fibre depends on the test result of the first two groups. Three tests are conducted for each component of specimen group. The applied vertical force and resulting deformation is recorded up to the failure stage of the brick. This is observed based on the appearance of vertical cracks near the brick corners and in the middle of vertical surface.

The Figure 9(a) represents the compressive strength, performance of the first group specimens L1 to L10 comprising soil and lime. Here, the specimen demolition occurs instantly and the load carrying capacity gets affected after the occurrence of several cracks on the corners as presented in Figure $8(a)$. It is inferred that the compressive strength increases gradually up to a range of $6 \%$ addition of lime; on further addition of lime there is a rapid increase in compressive strength and reaches a maximum value of $1.59 \mathrm{~N} / \mathrm{mm}^{2}$ corresponding to $9 \%$ lime composition of specimen L6. Lower compressive strength values are recorded on the corners due to high load concentration and early dryness in the specimen corners. Beyond $9 \%$ composition, the compressive strength decreases gradually with respect to addition of lime content.

The specimens with pineapple fibres (F1 to F10) are subjected to compressive test as shown in Figure $9(b)$. The compressive strength increases rapidly up to $0.4 \%$ addition of fibre content that corresponds to a maximum value of $3.52 \mathrm{~N} / \mathrm{mm}^{2}$. Beyond $0.4 \%$, specimen failure occurs due to the formation of vertical cracks at the corners. These cracks are propagated to the middle vertical plane of the specimen as shown in Figure $8(b)$. This phenomenon occurs due to the homogeneousness of the fibres in the specimen that gradually prolong the vertical cracks to the middle portion. The homogeneity of the specimen depends on the percentage content of fibres, and hence the increased rate of pineapple fibre content leads to more homogeneity and higher the dispersion of compressive stress. This inference correlates with the concept reported in literature [18] states that the addition of $5 \%$ straw and palm fibres tends to higher homogeneous effect which increases the compressive stress dis tribution.

In specimens L1 to L10, the entire corners get crushed immediately and the cracks never prolong towards the centre due to the lack of linking medium fibre as shown in Figure 8(a). This leads to lesser compressive strength capacity. Therefore, the soil particles and lime certainly not impact on crack extension, whereas the fibre composition greatly impacts. The inclusion of pineapple fibres prevents crack opening by shearforce transmission through link to the composition parts. According to literature [19], the compressive strength was reduced with respect to the addition of fibre content beyond its nominal range, which in turn weakens the connection and friction between soil 
particles. Correspondingly, it is observed in this study that there is a reduction in compressive strength due to increased fibre content beyond $0.4 \%$ inclusion of pineapple fibre.

The blending of pineapple fibres with the soil-lime composition (L6F1 to L6F10) represented in Figure $9(c)$ is revealed as significant up to some extent and further, the strength gets denied. The compressive strength profile of the composite represented in Figure 9(c) exhibits almost similar performance with the Figure $9(b)$. However, there is a considerable improvement in the compressive strength due to the inclusion of $9 \%$ lime content. The increase in compressive strength from $0.1 \%$ to $0.4 \%$ fibre content is because of the increased frictional resistance between soil-lime particles and the fibres. The distribution of cracks is prevented by the union of soillime and fibres which link across the cracks [20]. The maximum compressive strength attained is $4.1 \mathrm{Mpa}$ that corresponds to $0.4 \%$ fibre and $9 \%$ lime content. Once peak strength is achieved, the fibres start to overlay each other which result in poor cohesion with the soil ensuing in the weakening strength of the composites [21]. The addition of lime also plays a significant role in the bond strength development of the composites and sealing the pores. Constituents such as silica, calcium oxide and alumina produce a gel that interlinks with the soil particles and seal the pores to achieve enhanced strength [22].

The experimental association between the compressive strength and modulus of rupture is illustrated in Figure 10. The robust regression analys is is performed to present the linear correlation between compressive strength and bending strength. The compressive and bending strength of the three groups of specimen model increases mutually, which exhibits significant correlation and the coefficient of determination $\mathrm{R} 2=0.921$ for the specimens $\mathrm{L} 1$ to $\mathrm{L} 10$, 0.941 for F1 to F10 and 0.979 for the specimens L6F1 to L6F10 as mentioned in Figures $10(a),(b)$ and $(c)$ respectively.

As the determination coefficient R2 is close to 1 , this signifies an average $94 \%$ rate of strong bond relationship between the modulus of elasticity and compressive stress. Therefore, modulus of elasticity can easily be determined from the compressive stres s factor as mentioned in the proposed simple linear Equations 4, 5 and 6.

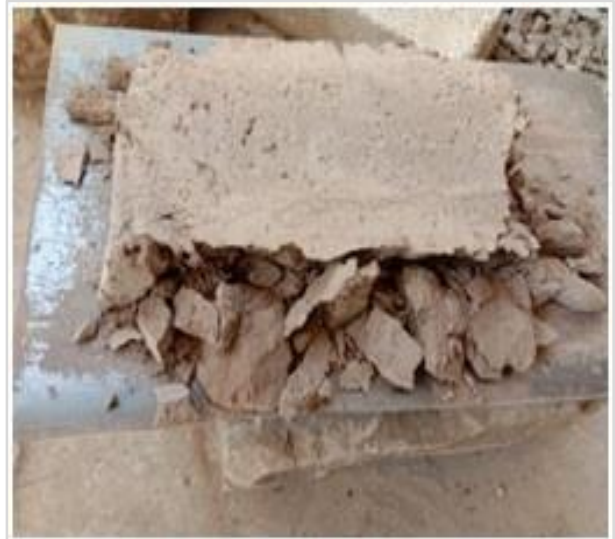

a) Group 1

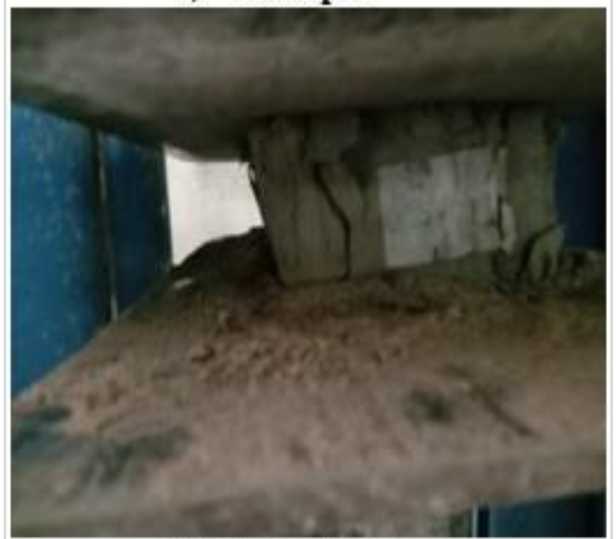

b) Group 2

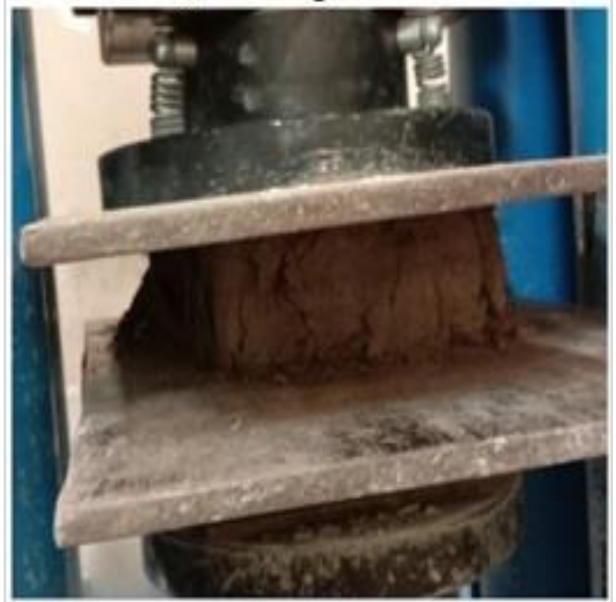

c) Group 3

Figure 8 Compres sive strength test and failure pattern of brick specimen 

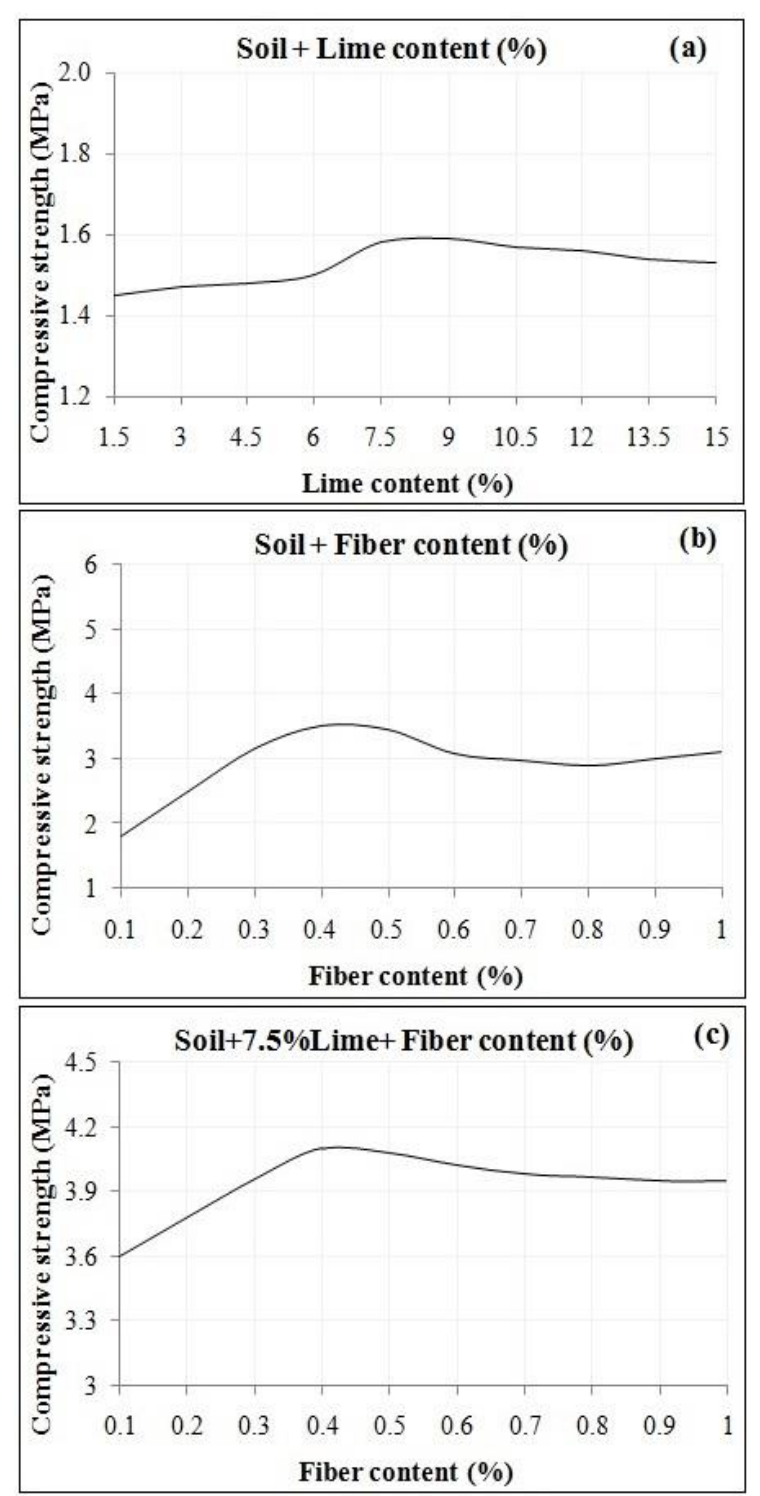

Figure 9 Compressive strength performances of various compositions

$E_{c}=165.7 f_{c}-230.7 ;$ Soil + Lime composition (4)

$E_{c}=20.39 f_{c}-28.41$; Soil + Fiber composition

$E_{c}=54.71 f_{c}-162.6 ;$ Soil + Lime +

Fiber composition

5.2Effect of fibre and lime content on the tensile strength

Mechanical behaviour of reinforced and unreinforced adobe brick in tension is examined by conducting three point bending test on all three specimen groups. In Figure 11, the curve illustrates the flexural strength of the specimens corresponding to different percentages of compositions. The Figure 11(a) represents the specimens without fibre content (L1 to L10), which records a maximum tensile strength as $0.111 \mathrm{~N} / \mathrm{mm}^{2}$ corresponding to specimen L6 9\% lime composition. This value is similar to the compressive strength of concrete of same specimen and is observed that the tensile strength depends on the bond between the soil particles through lime paste along the failure plane. In general, tensile strength of soil relies on the cohesion of the soil, whereas in the case of saturated soil, the cohesion is mostly characteristic to electrostatic attraction and bonds between particles. The cohesion of unsaturated soils corresponds with suction. The approximate average tensile strength of brick specimen is a 0.58 times cohesion value which is slightly higher than the empirical value reported by [23], due to the lime content on the specimen.

The specimen with fibre content (F1 to F10) as shown in Figure 11(b) improves the tensile strength of the brick specimen. The flexural strength increases rapidly with the addition of fibre content up to the range of $0.4 \%$ and the maximum value is recorded as 0.51 $\mathrm{N} / \mathrm{mm}^{2}$ corresponding to $0.4 \%$ fibre content. This is mostly due to the sliding of fibres in the soil matrix controlled by the interfacial mechanical interactions between fibre surface and soil particles. Accordingly, fibres exhibit the potentiality to distribute the tensile load to the soil matrix of brick and hence intensify tensile strength. Therefore, the pineapple fibre reinforcement combined with Hawassa soil offers a noticeable tensile strength enhancement.

The specimen tensile strength of pineapple fibre and lime composition (L6F1 to L6F10) as shown in Figure $11(c)$ is similar to the compres sive strength and hence the compressive strength increasing and decreasing attributes are same as that of tensile strength. The maximum tensile strength recorded is $0.780 \mathrm{~N} / \mathrm{mm}^{2}$ corresponding to $9 \%$ addition of lime and $0.4 \%$ pineapple fibre composition due to the increased frictional resistance between soil-lime particles and the fibres. Another significant factor responsible for the increase of tensile strength is the addition of fibres to the soil lime content that enhances the interface between soil matrix and fibres for better resistance against splitting. On further addition of pineapple fibre the flexural strength gradually reduces due to the overlay of fibres each other which result in poor cohesion with the soil ensuing in the weakening strength of the composites [21]. Duan and Zhang [22] reported that there is a delay in the extension of crack due to the linking of the soil matrix by the fibres. In addition, the tensile failure of the specimen is more gradual with the increased fibres content with soillime 
matrix and hence more ductile behaviour is also reported in earlier studies [24].

To analyse the regression robustness between the tensile modulus and tensile strength, the polynomial correlation was performed as represented in Figure 12. It is inferred that the tensile strength and tensile modulus increases mutually and possess a better correlation at an average rate of $86.7 \%$. The coefficient of determination, R2 is equal to 0.910 for the specimens L1 to L10, 0.806 for F1 to F10 and 0.888 for the specimens $\mathrm{L} 6 \mathrm{~F} 1$ to $\mathrm{L} 6 \mathrm{~F} 10$ as mentioned in Figures 12(a), (b) and (c) respectively. This indicates the strengthened robustness between the tensile modulus and tensile strength factors, and hence the tensile modulus is calculated effortlessly from the tensile strength by using the proposed simple polynomial Equations 7,8 and 9 as shown below.

$E_{t}=-21810 f_{t}^{2}+4864 f_{t}-254.1$; Soil +

Lime composition

$E_{t}=-88.11 f_{t}^{2}+102.6 f_{t}+33.55 ;$ Soil +

Fiber composition

$E_{t}=-575.5 f_{t}^{2}+929.1 f_{t}-311.4 ;$ Soil + Lime +

Fiber composition

The compressive and tensile strength model of specimen increases mutually as shown in the Figure 12. It infers a significant association between each composition and the coefficient of determination, $\mathrm{R} 2=0.985$ for the specimens $\mathrm{L} 1$ to $\mathrm{L} 10,0.886$ for $\mathrm{F} 1$ to F10 and 0.964 for the specimens $\mathrm{L} 6 \mathrm{~F} 1$ to $\mathrm{L} 6 \mathrm{~F} 10$ as mentioned in Figures 13( $a),(b)$ and (c) respectively.

This represents a compressively strong brick also enables a strong tension and hence the compressive testing effectively facilitates to predict the tensile strength, which is in perfect harmony with the existing literature [20]. As an averaged statistic, the flexural strength equals $6.9 \%, 14.5 \%$ and $19 \%$ of the compressive strength of the specimens L1 to L10, F1 to F10 and L6F1 to L6F10 respectively. The proposed linear Equations 10, 11 and 12 mentioned below are used to calculate the flexural strength of brick for various compositions using compressive strength test result data.

$f_{t}=0.069 f_{c} ;$ Soil + Lime composition

$f_{t}=0.124 f_{c}+0.059 ;$ Soil + Fiber composition(11)

$f_{t}=0.161 f_{c}+0.115$; Soil + Lime + Fiber composition
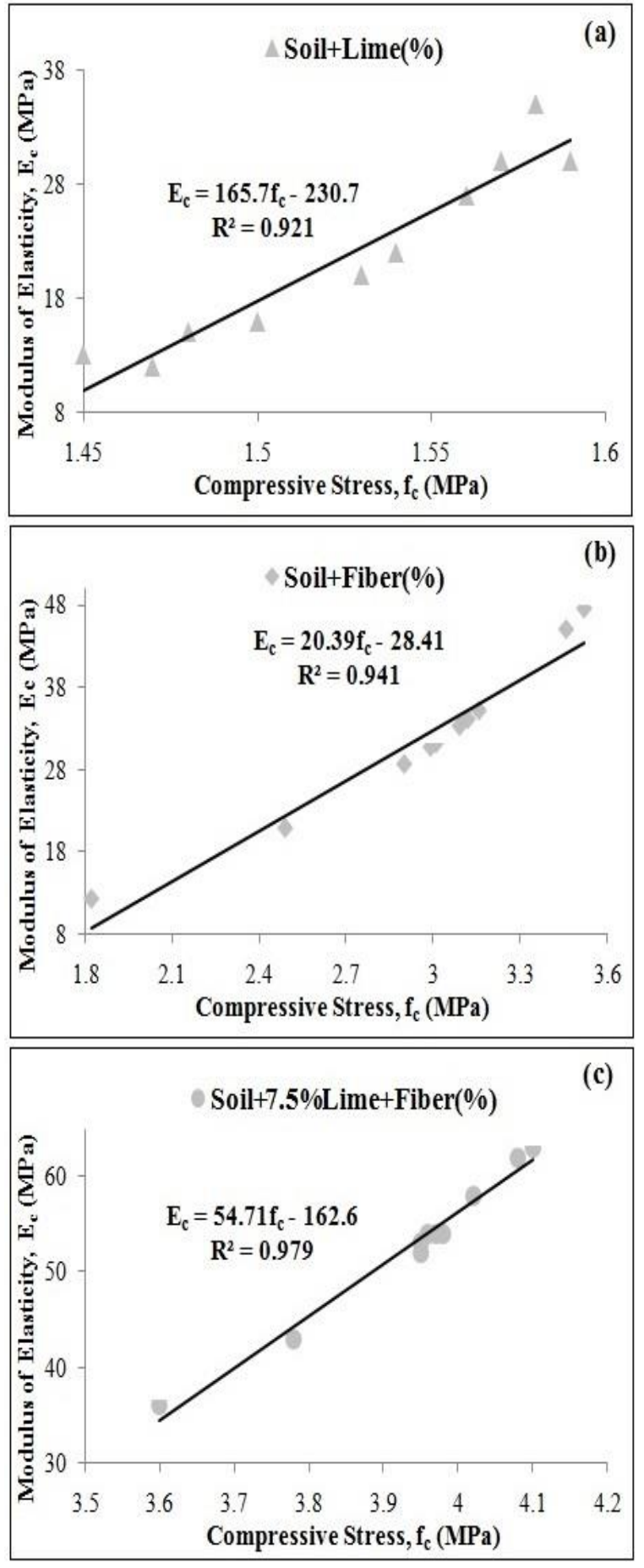

Figure 10 Regression analyses of compressive strength and modulus elasticity 

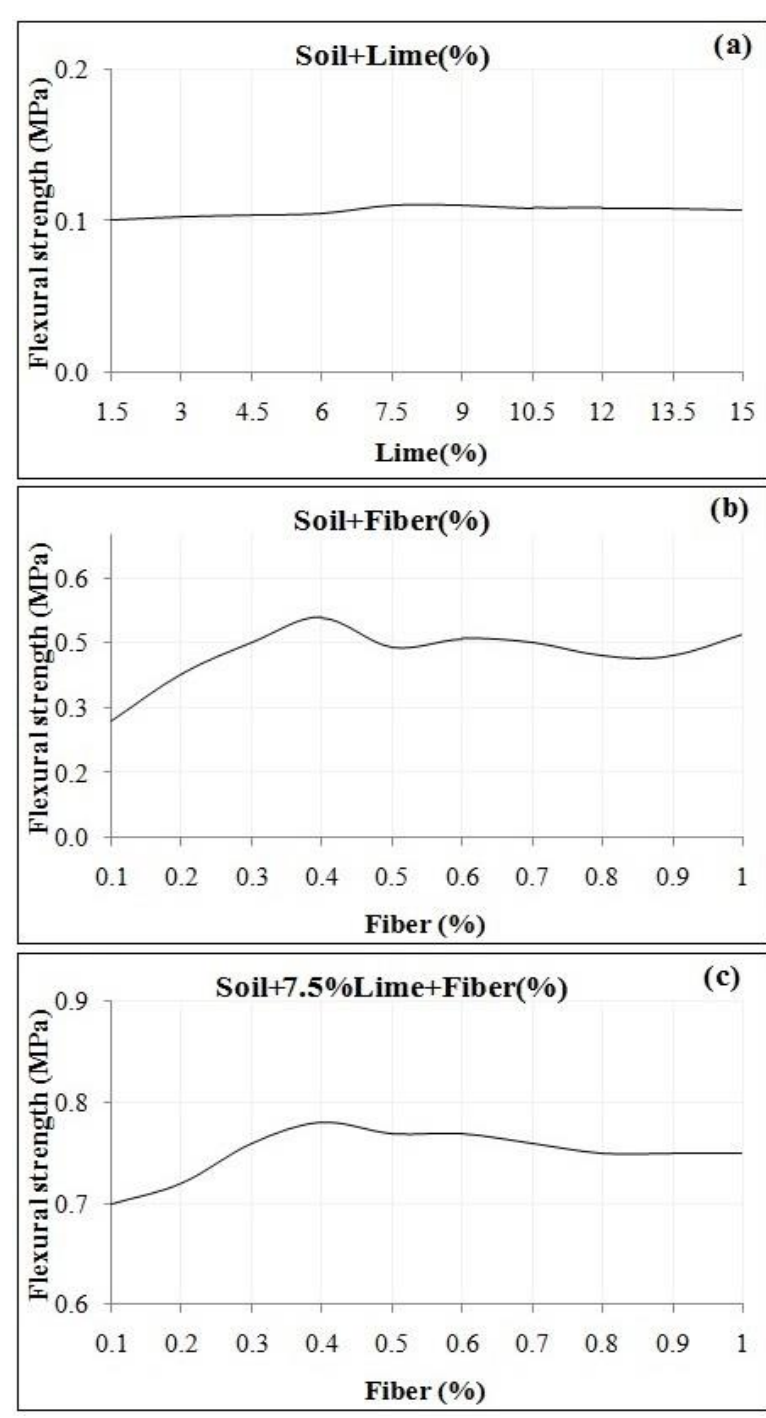

Figure 11 Flexural strength performances of various compositions

5.3Effect of lime and fibre content on the tensile load verses displacement behaviour

The influence of the lime and pineapple fibres on the tensile load verses dis placement behaviour is shown in the Figure 14. It is found that the tensile load increases with increasing displacement rapidly up to the ultimate value where the tensile cracks are formed. Henceforth in the specimens without fibre content (L1 to L10), the tensile load falls to zero rapidly, this signifies the inelastic nature of the specimen for failure. In case of specimens reinforced with fibres (F1 to F10) the behaviour is similar up to the ultimate tensile load, beyond there is a reduction in the applied load due to the total displacement of specimen focused on the bond slipping of the fibres in either side of the crack. However, due to the availability of fibres, a residual

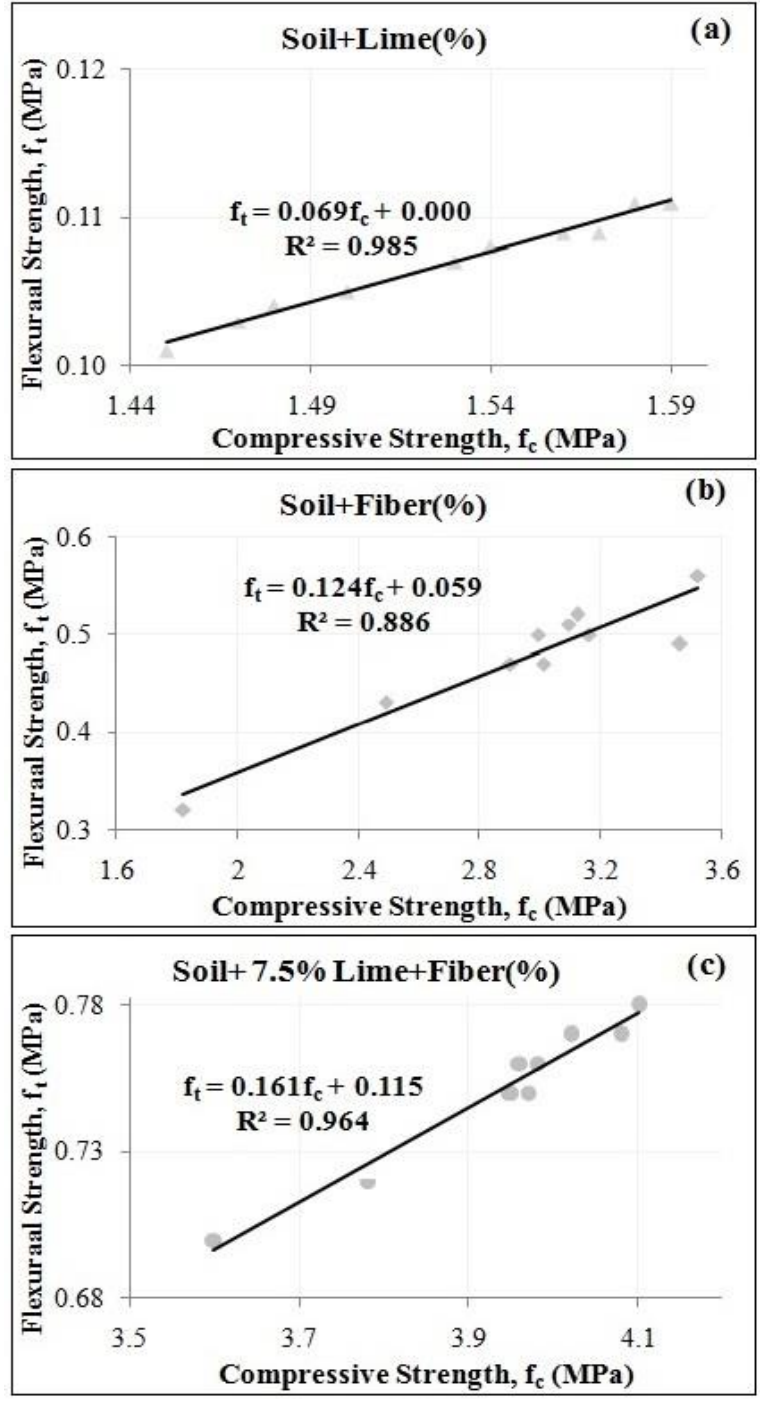

Figure 12 Tensile strength verses tensile modulus

tensile load is sustained after the ultimate load. This declares that the addition of reinforced fibres in the Hawassa soil is efficient in enhancing ductility failure of brick. The specimen composition with both lime and fibres F4L1 to F4L10 also experience similar behaviour, up to ultimate tensile load, further there is a sudden reduction in the tensile load and maintain the enhanced residual load, which is a more improved behaviour than the soil with fibre compositions. This is due to the inclusion of lime content which improves the bond strength and diminishes the bond slipping between the soil particles and fibres. Hence the inclusion of lime and fibres on Hawassa soil brick enhances the ductility and sudden collapse of the structure during seismic. 

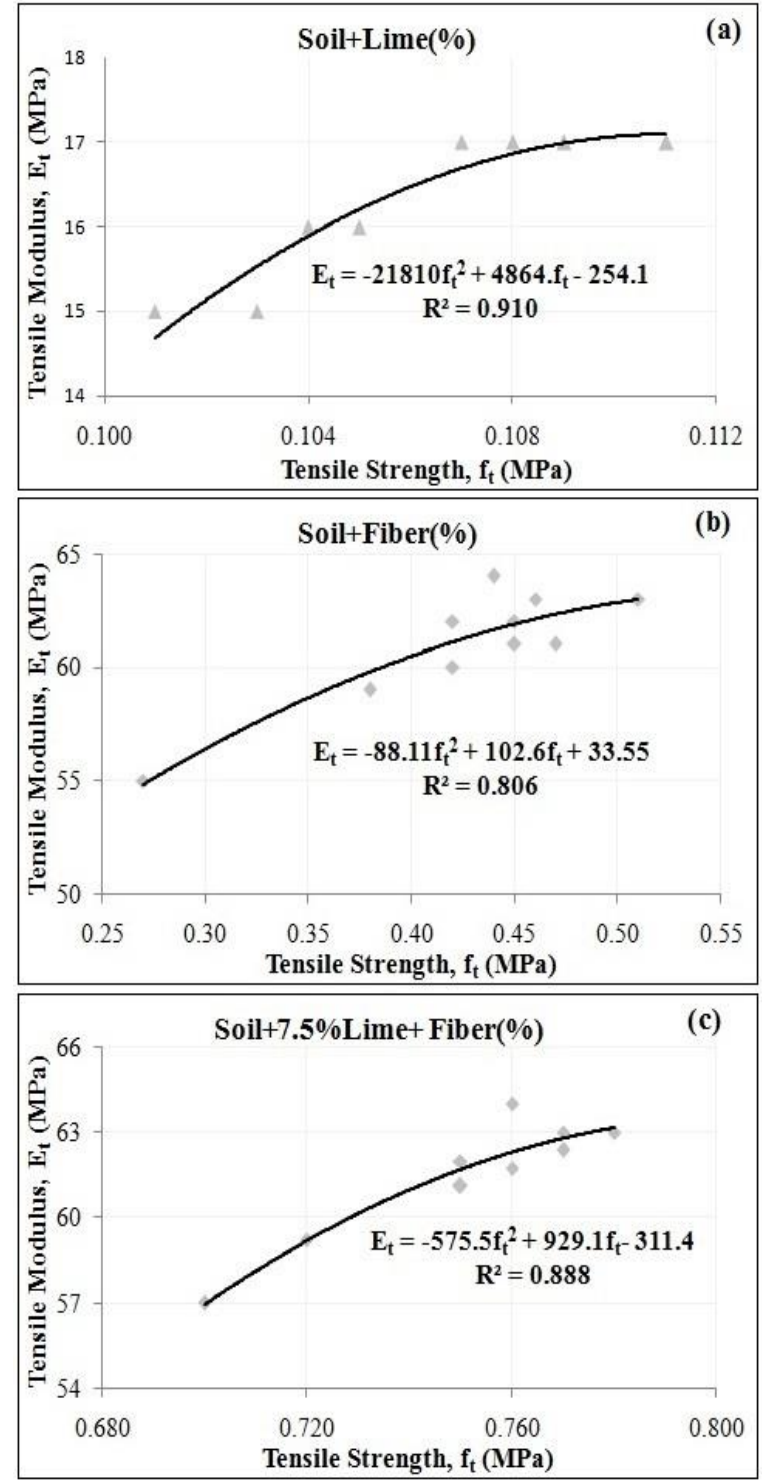

Figure 13 Experimental relationships between brick compressive and flexural strength

\subsection{Durability test on rain}

The durability testing based on water absorption is not essential in case of plastered un-burnt brick masonry [24]. Even though, the durability property of the unburnt brick is tested by immersing it in the water for 30 minutes and is observed that there is no disintegration in the brick specimen of group 2 and 3 as shown in Figure 15(a). Moreover, this study conducts the direct field test to check the durability by exposing the three groups of brick specimen towards rain for one month and its corresponding effect of erosion is studied. Fortunately, the rain exposed testing locality experiences rainfall for at least one hour per day. On completion of testing after one month duration, the erosion rate recorded in the first group of specimens is very high due to its edges and corners gets faded away and hence this specimen composition is unsatisfactory. Whereas, the second and third groups of brick specimens experience a negligible deterioration rate less than $8 \mathrm{~mm}$ and $5 \mathrm{~mm}$, respectively, due to its mixed composition with fibre as shown in Figure 15(b). If plastering is applied on the bricks the abrasive effect of water on adobe brick is completely negligible.

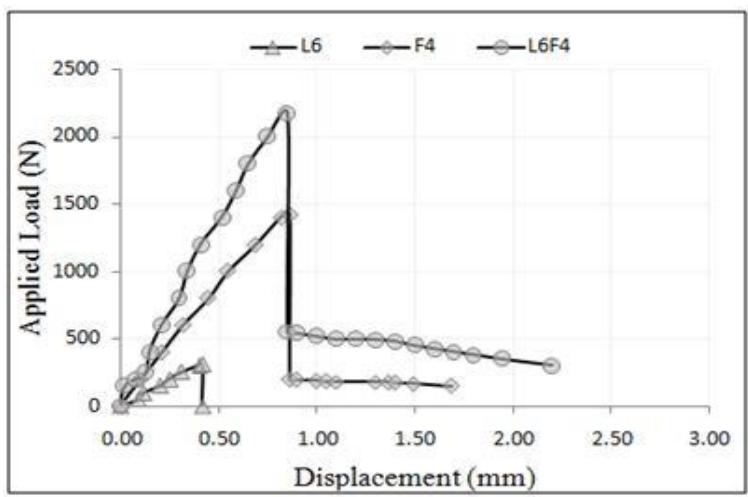

Figure 14 Tensile load verses displacement behavior
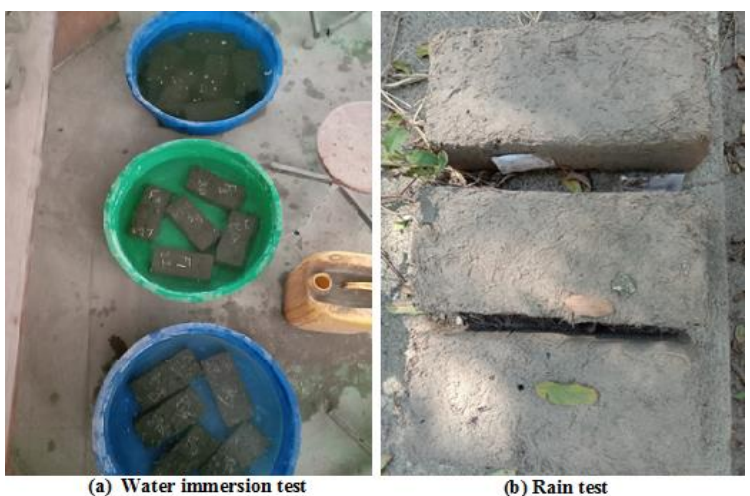

Figure 15 Durability test

\section{Discussion}

From the experimental results, it is inferred that the adobe bricks made of lime ingredient get collapsed suddenly due to the formation of cracks. The entire corners get cracked rapidly and there is no possibility to propagate these cracks towards the middle of the specimen because of the lack of linking element in the adobe bricks. Hence this kind of adobe bricks exhibits smaller load carrying capacity, poor load sustainability and the failure occurrence is sudden. This motivates this research to incorporate a suitable linking element. For this purpose, laboratory testing was conducted for various natural fibres and finally the pineapple leaf fibre is selected due to its superior tensile capacity. 
The beneficial aspect of this composite is improved cohesion property between the soilparticles due to the presence of lime content. Accordingly, the second group of specimens is made of pineapple leaf fibre without any addition of lime content. Under this condition, the load carrying capacity is improved and the failure is occurring due to corner crack. These corner cracks are propagated towards the middle of the specimen due to the linking element called pineapple leaf fibre. Here, the sudden occurrence of failure is avoided with an added advantage of enhanced load carrying capacity. Moreover, the inclusion of pineapple leaf fibre prevents crack opening by shear force transmission through the link to the composite parts. Therefore, this composite is proved as robust, sustainable and durable and is considered as proposed 1 adobe brick. It is found that the higher rate of pineapple leaf fibre content inclusion leads to a reduction in the strength, because the pineapple leaf fibre weakens the connection and friction between the soil particles [19]. The third group includes composites of pineapple leaf fibre and lime which comprises the advantageous feature as enhanced strength of adobe brick. Here, the distribution of crack is prevented by the union of soil - lime and fibres which link across the cracks [20]. The inclusion of lime plays a significant role in improving the bond strength between the pineapple leaf fibre and soil [22].

6.1Comparative study of conventional and proposed method

An existing practice of adobe brick making is reported in a recent literature [25] is referred as a conventional method throughout this paper. The comparative analysis between the conventional method and the proposed concepts are tabulated in Table 4 by enlightening the imperfection in the conventional method and remedial actions taken in the proposed methods by conducting laboratory investigation. A critical analysis between the conventional and proposed methods in terms of ingredients, the optimum percentage of ingredients, easy to handle, compressive strength, tensile strength, residual load and cost analysis were conducted.

As far as the brick making ingredients are concerned the conventional method uses the teff straw as a reinforcing agent at an optimum ratio of $0.1 \%$ and is to be noted that teff straw is easily degradable which complicates the robustness of the brick. Hence the proposed strategy utilizes pineapple leaf fibre at an optimum ratio of $0.4 \%$ as the reinforcing element which possesses high tensile strength capability. The laboratory results show that the compressive strength of the conventional method varies from 0.447 to 0.708 Mpa, whereas the proposed 1 and 2 method adobe brick groups are $3.52 \mathrm{MPa}$ and $4.1 \mathrm{MPa}$ respectively. Similarly, the tensile strength of the proposed 1 and 2 methods is $0.51 \mathrm{MPa}$ and $0.78 \mathrm{MPa}$, respectively and the conventional method value varies from 0.05 to $0.065 \mathrm{Mpa}$. The test results infers that the proposed 1 and 2 concepts satisfy the minimum requirement as per the CBC code [26] and the conventional method fails to attain the minimum requirement. This shows the superiority of the proposed 1 and 2 concepts as compared to the conventional brick in terms of mechanical property investigation. In case of conventional method, the soil sample is collected from far distance regions which unnecessarily increase the transportation cost and hence the proposed methods employ soil from the native regions in favour of reducing the transportation charge. Consequently, the unit cost of proposed 1 and 2 method bricks rates economical as 0.78 and 0.83 Birr respectively, this is greatly reduced as compared to the conventionalbrick cost rate of 4 Birr. The brick production cost is estimated based on the present market rate of raw materials required and manpower as given in Table 5. Furthermore, in the proposed 1 and 2 methods an enhanced residual tensile load is recorded which makes the masonry more ductile and earthquake resistant. Complete list of abbreviations is shown in Appendix I.

\section{Limitation of the study}

The inclusion of fibre content beyond the nominal range leads to a reduction in the load carrying capacity, which deteriorates the connection and friction between the soil particles. The property of the soil may vary slightly within Hawassa, which may cause minor variation in the strength property of the masonry units. Moreover, the strength outcome of the masonry units depends on the water and soil lime ratio adopted by the construction engineer. Besides, the calculated cost of brick masonry unit was obtained based on the current market price at Hawassa and this may get varied.

Table 4 Comparis on of conventional and proposed approaches

\begin{tabular}{lllll}
\hline No. & Parameters & Conventional [26] & Proposed-1 & Proposed-2 \\
\hline 1 & Type & Adobe Block & Adobe Brick & Adobe Brick \\
\hline 2 & Size & $400 \times 200 \times 200 \mathrm{~mm}$ & $240 \times 112 \times 70 \mathrm{~mm}$ & $240 \times 112 \times 70 \mathrm{~mm}$ \\
\hline
\end{tabular}


J Jebasingh Daniel et al.

\begin{tabular}{|c|c|c|c|c|}
\hline No. & Parameters & Conventional [26] & Proposed-1 & Proposed-2 \\
\hline 3 & Soil Preferred & Far distance soil & Native soil & Native soil \\
\hline 4 & Ingredients & Teff straw & Pineapple fiber & Lime + Pineapple fiber \\
\hline 5 & Optimum ingredients $\%$ & $0.1 \%$ average & $0.40 \%$ & $7.5 \%+0.4 \%$ \\
\hline 6 & Average weight per unit & $>15 \mathrm{~kg}$ & $2.5 \mathrm{~kg}$ & $2.5 \mathrm{~kg}$ \\
\hline 7 & Ease of handling & Hard as it is heavier & Simple as it is lighter & Simple as it is lighter \\
\hline \multirow[t]{2}{*}{8} & \multirow[t]{2}{*}{ Compressive strength } & \multirow[t]{2}{*}{0.447 to $0.708 \mathrm{Mpa}$} & $\begin{array}{l}\text { Attained from optimal } \\
\text { proportion of additives }\end{array}$ & $\begin{array}{l}\text { Attained from the optimal } \\
\text { proportion of additives }\end{array}$ \\
\hline & & & $3.52 \mathrm{Mpa}$ & $4.1 \mathrm{Mpa}$ \\
\hline \multirow[t]{2}{*}{9} & \multirow[t]{2}{*}{ Tensile strength } & \multirow[t]{2}{*}{0.05 to $0.065 \mathrm{Mpa}$} & $\begin{array}{l}\text { Attained from the optimal } \\
\text { proportion of additives }\end{array}$ & $\begin{array}{l}\text { Attained from the optimal } \\
\text { proportion of additives }\end{array}$ \\
\hline & & & $0.51 \mathrm{Mpa}$ & $0.78 \mathrm{Mpa}$ \\
\hline \multirow[b]{2}{*}{10} & \multirow{2}{*}{$\begin{array}{l}\text { Compressive strength } \\
\text { according to CBC code } \\
{[25]}\end{array}$} & \multirow{2}{*}{ Unsatisfactory } & $\begin{array}{l}\text { The minimum required is } \\
2.06 \mathrm{Mpa}\end{array}$ & $\begin{array}{l}\text { The minimum required is } \\
2.06 \mathrm{Mpa}\end{array}$ \\
\hline & & & $\begin{array}{ll}\text { Gained } & 3.52 \\
\text { Satisfactory }\end{array}$ & $\begin{array}{l}\text { Gained } 4.1 \quad \text { Mpa- } \\
\text { Satisfactory }\end{array}$ \\
\hline \multirow{2}{*}{11} & \multirow{2}{*}{$\begin{array}{l}\text { Compressive strength } \\
\text { according to } \mathrm{CBC} \text { code } \\
{[25]}\end{array}$} & \multirow{2}{*}{ Unsatisfactory } & $\begin{array}{l}\text { The minimum required is } \\
0.35 \mathrm{Mpa}\end{array}$ & $\begin{array}{l}\text { The minimum required is } \\
0.35 \mathrm{Mpa}\end{array}$ \\
\hline & & & $\begin{array}{ll}\text { Gained } 0.51 & \text { Mpa- } \\
\text { Satisfactory } & \end{array}$ & $\begin{array}{ll}\text { Gained } 0.78 & \text { Mpa- } \\
\text { Satisfactory } & \end{array}$ \\
\hline 12 & Residual load & Not conducted & $\begin{array}{l}\text { The residual tensile load } \\
\text { is sustained }\end{array}$ & $\begin{array}{l}\text { The enhanced residual } \\
\text { tensile load is sustained }\end{array}$ \\
\hline 13 & Durability test on rain & Not conducted & $\begin{array}{l}\text { deterioration rate less } \\
\text { than } 8 \mathrm{~mm}\end{array}$ & $\begin{array}{l}\text { deterioration rate less than } \\
5 \mathrm{~mm}\end{array}$ \\
\hline 14 & Unit cost & 4 Birr & 0.78 Birr & 0.83 Birr \\
\hline
\end{tabular}

Table 5 Estimation of brick production cost

\begin{tabular}{lll}
\hline Details & Proposed-1 & Proposed-2 \\
\hline Volume of one brick $\left(\mathrm{m}^{3}\right)$ & 0.002 & 0.002 \\
\hline Cost of soil for unit brick (Birr) & Free of cost & Free of cost \\
\hline Weight of one brick (kg) & 2.5 & 2.5 \\
\hline Weight of 7.5\% lime & - & 0.1875 \\
\hline Weight of 0.4 \% Pineapple fiber & 0.010 & 0.010 \\
\hline Cost of 1kg of lime (Birr) & - & 5 \\
\hline Cost of lime for unit brick (Birr) & - & 0.05 \\
\hline Cost of 1kg of pineapple fiber (Birr) & 20 & 20 \\
\hline Cost of Pineapple fiber for unit brick (Birr) & 0.08 & 0.08 \\
\hline Labor cost per unit brick (Birr) & 0.7 & 0.7 \\
\hline Total cost of one unit brick (Birr) & 0.78 & 0.83 \\
\hline
\end{tabular}

\section{Conclusion and future work}

An engineered and economically feasible brick construction method was proposed for the poor inhabitants of Hawas s a village and adobe brick design modelling equations are presented. Amongst the three groups of brick test specimens, the optimum strength is recorded for the composites belongs to group 2 having $0.4 \%$ pineapple fibre with Hawassa soil and group 3 possessing $7.5 \%$ lime and $0.4 \%$ pineapple fibre. The maximum compressive strength is recorded as $3.52 \mathrm{MPa}$ and $4.1 \mathrm{MPa}$ for the groups 2 and 3 respectively, which is 5 and 6 times respectively greater than the conventional specimens. Moreover, the optimal flexural strength is recorded at an improved rate of $0.51 \mathrm{Mpa}$ and $0.78 \mathrm{Mpa}$ for the groups 2 and 3 respectively. These improved strength 732 recording rates ensure the standard requirement according to the $\mathrm{CBC}$ code. The test results confirms that a residual tensile load sus tains beyond the ultimate load, which reveals the addition of reinforced fibres on the Hawassa soil is efficient in enhancing ductility failure of brick. The durability of the specimens belongs to group 2 and 3 experiences a negligible deterioration rate less than $8 \mathrm{~mm}$ and $5 \mathrm{~mm}$ respectively. Cost estimation analysis evidences the estimated cost as 0.83 birr per brick including labour cost, which is $72 \%$ lesser as compared to conventional bricks. Hence it is considered as reasonable expenditure for the low-income community. The future extension of the study is to investigate the seismic behaviour and performance of same masonry unit wall under seismic loading. 
Acknowledgment

None.

Conflicts of interest

The authors have no conflicts of interest to declare.

\section{References}

[1] Babé C, Kidmo DK, Tom A, Mvondo RR, Boum RB, Djongy ang $\mathrm{N}$. Thermomechanical characterization and durability of adobes reinforced with millet waste fibers (sorghum bicolor). Case Studies in Construction Materials. 2020; 13:1-13.

[2] Olacia E, Pisello AL, Chiodo V, Maisano S, Frazzica A, Cabeza LF. Sustainable adobe bricks with seagrass fibres. Mechanical and thermal properties characterization. Construction and Building Materials. 2020.

[3] Bertelsen IM, Belmonte LJ, Fischer G, Ottosen LM. Influence of synthetic waste fibres on drying shrinkage cracking and mechanical properties of adobe materials. Construction and Building Materials. 2021.

[4] Tavares GR, Magalhães MS. Effect of recycled PET fibers inclusion on the shrinkage of adobe brick. Academic Journal of Civil Engineering. 2019; 37(2):545-50.

[5] Ige O, Danso H. Physico-mechanical and thermal gravimetric analy sis of adobe masonry units reinforced with plantain pseudo-stem fibres for sustainable construction. Construction and Building Materials. 2021.

[6] Kafodya I, Okonta F, Kloukinas P. Role of fiber inclusion in adobe masonry construction. Journal of Building Engineering. 2019.

[7] Ouedraogo M, Dao K, Millogo Y, Aubert JE, Messan A, Seynou M, et al. Physical, thermal and mechanical properties of adobes stabilized with fonio (digitaria exilis) straw. Journal of Building Engineering. 2019; 23:250-8.

[8] Muñoz P, Letelier V, Muñoz L, Bustamante MA. Adobe bricks reinforced with paper \& pulp wastes improving thermal and mechanical properties. Construction and Building Materials. 2020.

[9] Sudhir MR, Beulah M, Rai PS, Gayathri G. A microstructure exploration and compressive strength determination of red mud bricks prepared using industrial wastes. Materials Today: Proceedings. 2021; 46:163-9.

[10] Malkanthi SN, Balthazaar N, Perera AA. Lime stabilization for compressed stabilized earth blocks with reduced clay and silt. Case Studies in Construction Materials. 2020; 12:1-8.

[11] Gebino G, Muhammed N. Extraction and characterization of ethiopian pineapple leaf fiber. Current Trends in Fashion Technology \& Textile Engineering. 2018; 4(3):20-6.

[12] Lopattananon N, Panawarangkul K, Sahakaro K, Ellis B. Performance of pineapple leaf fiber-natural rubber composites: the effect of fiber surface treatments. Journal of Applied Polymer Science. 2006; 102(2):1974-84.
[13] Mishra S, Misra M, Tripathy SS, Nayak SK, Mohanty AK. Potentiality of pineapple leaf fibre as reinforcement in PALF-polyester composite: surface modification and mechanical performance. Journal of Reinforced Plastics and Composites. 2001; 20(4):32134.

[14] Parvej AD, Usmani TM, Danish M. Growth of pineapple cultivation: a spatio-temporal analysis in India. Growth. 2020; 4(2):505-11.

[15] En T. Natural stone test methods-determination of compressive strength. Turkish Standards Institute, Ankara. 2007.

[16] En B. 1015-11, Methods of test for mortar for masonry. Determination of Flexural and Compressive Strength of Hardened Mortar. 1999.

[17] Jones RM. Stress-strain relations for materials with different moduli in tension and compression. AIAA Journal. 1977; 15(1):16-23.

[18] Aymerich F, Fenu L, Meloni P. Effect of reinforcing wool fibres on fracture and energy absorption properties of an earthen material. Construction and Building Materials. 2012; 27(1):66-72.

[19] Silveira D, Varum H, Costa A, Martins T, Pereira H, Almeida J. Mechanical properties of adobe bricks in ancient constructions. Construction and Building Materials. 2012; 28(1):36-44.

[20] Chan CM. Effect of natural fibres inclusion in clay bricks: physico-mechanical properties. International Journal of Civil and Environmental Engineering. 2011; 5(1):7-13.

[21] Danso H. Use of agricultural waste fibres as enhancement of soil blocks for low-cost housing in Ghana. Doctoral Dissertation, University of Portsmouth, School of Civil Engineering and Surveying. 2015.

[22] Duan XL, Zhang JS. Mechanical properties, failure mode, and microstructure of soil-cement modified with fly ash and poly propy lene fiber. Advances in Materials Science and Engineering. 2019.

[23] Mielniczuk B, El-Youssoufi SM, Hueckel T. The mechanics of air entry of drying-cracking soils: PHYSICAL models. Computers and Geotechnics. 2021.

[24] Vasić MV, Pezo LL, Radojević Z. Optimization of adobe clay bricks based on the raw material properties (mathematical analysis). Construction and Building Materials. 2020.

[25] Chandrasekar MK, Zewdie M, Nigussie T. Engineered practices of adobe masonry production in Ziway, Ethiopia. Zede Journal. 2019; 37:13-25.

[26] California building standards commission. California building code. International Conference of Building Officials. 2001. 


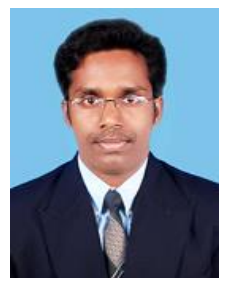

J Jebasingh Daniel received his Bachelor's degree in Civil Engineering from Anna University during 2007 and he graduated his Master's in Structural Engineering at Anna University during 2010. He is currently a Senior Lecturer (2012-ongoing) at Department of Civil Engineering, Institute of Technology, Hawassa University, Ethiopia. During 2010-2012 he worked as a Project Engineer and Senior Engineer at Indian Institute of Technology and L \& T Construction. Formerly he served as Project Engineer (2007-2008) at SAAG-RR construction. His research interests include Structural Engineering, Earth Quake Engineering, Construction Engineering and Wind Engineering. He received Best Academic Year Performance 2013/2014 award issued for best contribution as teaching faculty in Civil Engineering, Institute of Technology, Hawassa University, Ethiopia and Enthusiastic New Comer award issued for best contribution as Trainee Engineer in SAAG-RR infra-Limited during 2008.

Email: jdaniel@hu.edu.et

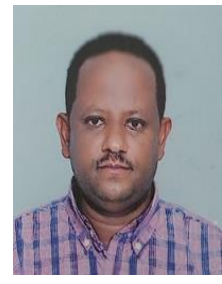

Desta Basoro is currently Dean (2015ongoing) at Faculty of Civil Engineering, Institute of Technology, Hawassa University, Ethiopia and former Department Head (2013-2015) at Hawassa University. He experienced as a Professional Engineer at an Ethiopian Government Organization. During 2007 he received his BSc in Urban Planning and MA degree in Urban Management during 2011 from Ethiopian Civil Service University.

Email: destab@hu.edu.et

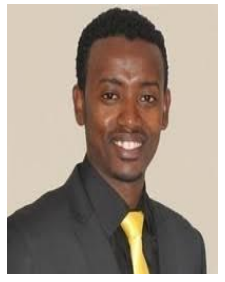

Mehretu Gebrie Doyamo is a senior Lecturer and a Head of the Department (2015-ongoing) of Civil Engineering at Institute of Technology, Hawassa University, Ethiopia. He experienced as a Professional Engineer III level license and he is a member of Ethiopian Civil Engineers Association. He also served as a part time project manager for two years at Hope Enterprises, Sintaro project and as a site engineer in building construction project at Netsanet Hailu Construction PLC. He received his $\mathrm{BSc}$ in Civil Engineering from Hawassa University and MSc in Civil Engineering for Risk Mitigation from Poly technic University of Milan.

Email: mehretu.gebrie@hu.edu.et

\begin{tabular}{lll}
\multicolumn{2}{l}{ Appendix I } \\
\hline S.No. & Abbre viation & Description \\
\hline 1 & CBC & California Building Standard Code \\
\hline 2 & CSEB & $\begin{array}{l}\text { Compressed Stabilized Earth Blocks } \\
\text { Depth of the transverse section of } \\
\text { specimen }\end{array}$ \\
\hline 3 & $\mathrm{~d}$ & $\begin{array}{l}\text { Compressive modulus of brick } \\
\text { specimen }\end{array}$ \\
\hline 4 & $\mathrm{E}_{\mathrm{c}}$ & Tensile modulus of brick specimen \\
\hline 5 & $\mathrm{E}_{\mathrm{t}}$ & Compressive Strength \\
\hline 6 & $\mathrm{f}_{\mathrm{c}}$ & Flexural Strength \\
\hline 7 & $\mathrm{f}_{\mathrm{t}}$ & $\begin{array}{l}\text { Span length between the supports } \\
\text { Transducers }\end{array}$ \\
\hline 8 & $\mathrm{~L}$ & Modulus of Rupture \\
\hline 10 & $\mathrm{LVDT}$ & $\begin{array}{l}\text { Ratio of tensile elastic modulustothe } \\
\text { compressive elastic modulus }\end{array}$ \\
\hline 11 & $\mathrm{n}$ & $\begin{array}{l}\text { Maximum load indicated by the } \\
\text { machine }\end{array}$ \\
\hline 12 & $\mathrm{P}$ & $\begin{array}{l}\text { Coefficient of determination } \\
\text { Width of the transverse section of } \\
\text { specimen }\end{array}$ \\
\hline 13 & $\mathrm{R}^{2}$ & $\mathrm{w}$
\end{tabular}

